\title{
Connecting Science, Technology and Education
}

The $4^{\text {th }}$ National Conference on Science, Technology and Innovation, held in Brasília ${ }^{1,2}$ from May $26^{\text {th }}$ to $28^{\text {th }}, 2010$ was a good opportunity for the government, the scientific society, entrepreneurs and university authorities to evaluate the present situation of innovation in Brazil and debate about a State policy for the next 30 years. A great deal of challenges and proposals were presented and defended. Concerning the chemical sector, some aspects of the thematic seminar 3 - Basic Science are worth pointing out: ${ }^{3}$

The basic or fundamental science involves knowledge generation and provides the seeds able to be transformed into technology and innovation. If in the twentieth century there was not a good understanding of how to relate basic science and technology, in the present century, the perception that innovation can arise from scientific discovery is still very recent.

The basic science point of view (and approach) prevailing till the second half of the twentieth century has been reviewed upon the disappearance, at the end of last century, of the subject frontiers within the natural sciences and the emergence of hybrid, changing, convergent fields of high complexity. Such transformation has been boosted earlier this century with the recognition of the technological convergence, which aims at the sciencetechnology unification, based on the combination of the nanotechnology, biotechnology, the information technology and the cognitive science. In this sense, both the scientific and the technological convergence emphasizes that the main focus is the study theme and not the subject itself.

In this new scenario, the main challenge at the nation level is having a State agenda for education, science, technology and innovation, with relevant development programs for the Brazilian basic science focused on merit, competence and creativity. The National Institutes' Program is a good example and an excellent beginning, but it is not enough.

The establishment of the National Institutes of Science and Technology (NIST) Program (http://www. cnpq.br/programas/inct/_apresentacao/index.html) has brought Brazil to a new threshold of actions related with science, technology and innovation, in accordance with a sustainable and interdisciplinary approach. However, the governance of the NIST and their institutional placement need to be established, in sync with the Universities, for, in several situations, the NIST gets bigger than the department or institute that houses it. So, the Science and Technology Ministry / National Council for Technological and Scientific Development and the Education and Culture Ministry interaction will be of vital importance for the NISTs to get a sustainable institutional support.

On the other hand, it is worth emphasizing that qualification is the key to the scientific and technological development. Brazil has a number of challenges to face in order to promote innovation and ensure the technological development of enterprises. One of them is investing in education quality and in the increase of the workers' education level. "For any kind of innovation, the human capital and the worker's qualification clearly represent the essential input to stimulate newness, productivity and competitiveness" "(http://www.protec.org.br/noticias. asp?cod=2020).

Several indicators confirm that Brazil has to increase its investments in education. The education level average of the Brazilian population under 15 or more is 4.3 years, inferior to that of 8.8 years of Argentina and 7.2 years of Mexico. About half the Brazilian young population has reading difficulties or can not read at all. According to the international program that assesses under-15 students (PISA), more than three-fourths of them face difficulty in solving the basic math operations. In South Korea, only $6 \%$ of them have difficulty or cannot read. The Brazilian students' math grades are inferior to the Mexican and Indonesian students'ones (http://www.protec.org.br/ noticias.asp?cod=2020).

What about Chemistry future? Much has been written about looking ahead to the future. There is a great convergence on the perception that researches are getting more and more interdisciplinary and that, among the main present themes, there is a special focus on energy and sustainable chemistry. No matter the theme on focus, the future demands the synergy of both experience and theory. The construction and transformation of molecules are directly related with the intermolecular forces, thus the necessity of the synergy between structure and chemical bonds.

The modern and advanced instrumental resources available nowadays, together with the ample advance in knowledge generation and diffusion, supply the proper and necessary conditions for Chemistry to flourish and yield fruits. The synergy between the two main chemistry fields - analysis and synthesis - is the path for the connection with Biology and other knowledge areas.

We need to educate to innovate and innovate to educate. The country is ready for the XXI century agenda, which requires focus and investments in innovation, sustainability and interdisciplinarity. This trinomial will only become possible with the strengthening of the connections of Science with Education and of Science with Technology and Innovation.

\section{Jailson B. de Andrade - UFBA} JBCS Editor

\section{References}

1. Mota, R.; J. Braz. Chem. Soc. 2010, 21, 573.

2. Pinto, A. C.; Galembeck, F. de Andrade, J. B.; J. Braz. Chem. Soc. 2010, 21, 191.

3. de Andrade, J.B., Lopes, W.A.; Abstracts of the $4^{\text {th }}$ National Conference on Science, Technology and Innovation, Brasília, Brasil, 2010, Plenary Session 3, pp. 163-167. 